\title{
A Mutational Alteration of the Tryptophan Synthetase of Escherichia coli
}

\author{
By F. GIBSON,* MARGARET I. GIBSON* AND C. YANOFSKY \\ Department of Biological Sciences, Stanford University, California, U.S.A.
}

\author{
(Received 4 October 1960)
}

\begin{abstract}
SUMMARY
A tryptophan auxotroph of Escherichia coli produced an altered tryptophan synthetase which could not convert indole to tryptophan but converted indole-3glycerol phosphate to indole. As distinct from the normal tryptophan synthetase, which also catalysed this reaction, both pyridoxal phosphate and serine stimulated the activity of the mutant enzyme system. Fractionation and chromatography of the mutant tryptophan synthetase separated it into its two protein components, $A$ and B. Examinations of the separated components showed that the A protein was normal, while the B protein was altere d. Studies of the effect of serine on the $\mathbf{p H}$ activity response of mutant preparations in the indole-3-glycerol phosphate $\rightarrow$ indole reaction demonstrated that different $\mathrm{pH}$-activity responses were obtained, respectively, in the presence and absence of serine. The curves obtained were characteristic of the serine-requiring and serine-non-requiring reactions, respectively, of normal tryptophan synthetase. The saturation curves of the mutant component $B$ by normal component $A$, with and without serine added, suggest that one role of serine and pyridoxal phosphate in the stimulation of the indole-3-glycerol phosphate $\rightarrow$ indole reaction is to bind together the $A$ and $B$ proteins in a catalytically effective complex.
\end{abstract}

\section{INTRODUCTION}

Studies performed with washed suspensions of two strains of Escherichia coli, a mutant requiring tryptophan for growth (strain 7-4) and a double mutant requiring tryptophan and serine or glycine (strain T2-15), indicated that serine was involved in the synthesis of indole from glucose and ammonium ion (Gibson, Jones \& Teltscher, 1956). Although it was also observed that serine was required for anthranilic acid formation, subsequent experiments with bacteria fully adapted to anthranilic acid synthesis showed that serine participated at some point between anthranilic acid and indole, in indole formation by the mutant strains (F. Gibson, unpublished observation). It was not obvious which reaction required serine since in $\boldsymbol{E}$. coli neither the conversion of anthranilic acid to indole-3-glycerol phosphate nor the conversion of indole-3-glycerol phosphate to indole normally involved this amino acid. Recently, DeMoss \& Bonner (1959) described a mutationally altered tryptophan synthetase of Neurospora crassa (from strain $t d_{71}$ ) which required serine and pyridoxal phosphate for the conversion of indole-3-glycerol phosphate to indole. Serine and pyridoxal phosphate are not required by the wild

* Present address: Bacteriology School, University of Melbourne, Parkville, N. 2, Victoria, Australia. 
type enzyme in this reaction. In view of this finding it was thought that the unexplained effect of serine on Escherichia coli mutant 7-4 might be due to a similar alteration of its tryptophan synthetase. This possibility was examined and an attempt made to localize the alteration to one of the two protein components of the bacterial tryptophan synthetase.

\section{METHODS}

Organisms. Three strains of Escherichia coli were used in this study. They were the parent strain (518), a mutant strain which required tryptophan for growth (7-4), and a double mutant derived from strain 7-4, which required tryptophan and serine or glycine for growth. These organisms have been described previously (Gibson et al. 1956).

Preparation of cell extracts. Organisms were grown on the mineral salts citrate mixture described by Vogel \& Bonner (1956) supplemented with 0.16\% (w/v) glucose and $0.005 \%(\mathrm{w} / \mathrm{v})$ acid-hydrolysed casein (neutralized before use). The glucose was added as a sterile solution after sterilization of the medium. For Escherichia coli 7-4, L-tryptophan (5 $\mu \mathrm{g} . / \mathrm{ml}$.) was included in the medium. One litre quantities of medium were inoculated with a 6-8 hr. culture in nutrient broth to give an initial population of about $10^{6}$ organisms $/ \mathrm{ml}$. The cultures were then shaken vigorously at $87^{\circ}$ for $16 \mathrm{hr}$. After harvesting the bacteria in a Sharples supercentrifuge they were washed once with cold $0.9 \%(w / v) ~ N a C l$ solution and

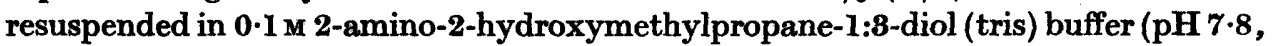
to give a final concentration of about $4 \times 10^{11}$ bacteria $/ \mathrm{ml}$. The suspension was then disrupted in a $10 \mathrm{Kc}$ Raytheon sonic oscillator for $20 \mathrm{~min}$. Cell debris was removed by centrifugation at $144,000 \mathrm{~g}$ in a Spinco Model $\mathrm{L}$ centrifuge for $30 \mathrm{~min}$. The supernatant fluid (crude extract) was stored at $-15^{\circ}$.

In addition to crude extracts, preparations obtained by precipitating tryptophan synthetase three times with ammonium sulphate were used (ASP enzyme). Solid ammonium sulphate was added to the crude extract to obtain $50 \%$ saturation, the addition being made at $0-5^{\circ}$ with stirring, and the stirring continued for a further $10 \mathrm{~min}$. after solution. The precipitate was separated by centrifugation at $4600 \mathrm{~g}$ for $10 \mathrm{~min}$. and dissolved in an amount of tris buffer $(0.1 \mathrm{M} ; \mathrm{pH} \mathrm{7.8)}$ equal to the original volume of extract. This precipitation was repeated twice and the final precipitate taken up in tris buffer and stored at $-15^{\circ}$.

Reagents. Reagents with the exception of those given below were obtained commercially and not further purified. Indole-3-glycerol phosphate was prepared by the method described by Yanofsky (1956) modified to the extent that it was formed by the indole + triosephosphate reaction (Yanofsky, 1959). The solution used contained $1.8 \mu$ mole indole-3-glycerol phosphate/ml.; 1-(o-carboxyphenylamino)-1-deoxyribulose-5-phosphate (anthranilic deoxyribulotide) was prepared as described by Smith \& Yanofsky (1960).

Normal A and B proteins from Escherichia coli T-3 and $E$. coli T-8, respectively, were purified on diethylaminoethyl (DEAE) cellulose columns (Crawford \& Yanofsky, 1958). Proteins A and B from $E$. coli mutant strain 7-4 will be referred to as $A_{7-4}$ and $B_{7-4}$.

Methods for assaying enzymic activity. The details of the methods used for estimating the activity of proteins $A$ and $B$ of tryptophan synthetase in the three 
reactions which they catalyse were described previously (Crawford \& Yanofsky, 1958; Yanofsky \& Stadler, 1958; Yanofsky, 1955, 1956). The conversion of indole8-glycerol phosphate to indole was carried out in a reaction mixture consisting of indole-3-glycerol phosphate and phosphate buffer $(\mathrm{pH} 7)$. DL-serine and pyridoxal phosphate were added where desired. Indole was measured by reaction with Ehrlich's reagent as described by Yanofsky (1955). The conversion indole-8-glycerol phosphate $\rightarrow$ tryptophan was carried out in a mixture of indole-3-glycerol phosphate, DL-serine, pyridoxal phosphate, $\mathrm{NaCl}$ and tris buffer (pH 7.8). The reaction was followed by measuring the disappearance of indole-3-glycerol phosphate. The remaining indole-3-glycerol phosphate was oxidized to indole-8-aldehyde by metaperiodate at $\mathrm{pH} 5$ and the absorption of indole-3-aldehyde formed was measured at $290 \mathrm{~m} \mu$. The conversion indole $\rightarrow$ tryptophan was carried out in the same reaction mixture as that just described except that indole was substituted for indole-3-glycerol phosphate. The reaction was followed by measuring indole disappearance. All tests were carried out in a final volume of $1 \mathrm{ml}$. at $37^{\circ}$.

One unit of tryptophan synthetase activity is defined as that amount of enzyme which catalyses the disappearance of $0 \cdot 1 \mu$ mole substrate or the formation of $0 \cdot 1$ $\mu$ mole product in $20 \mathrm{~min}$. at $37^{\circ}$.

Chromatography. Column chromatography was carried out on Reagent Grade 'Selectacel' diethylaminoethyl (DEAE) cellulose (Brown Company, Berlin, New Hampshire, U.S.A.). The preparation and use of such columns for the separation and purification of the components of tryptophan synthetase were described by Crawford \& Yanofsky (1958). In the present experiments a column $2 \times 90 \mathrm{~cm}$. was used. The gradient elution system consisted of $1 \mathrm{l}$. of $0.01 \mathrm{M}$-phosphate buffer (pH 7.0) in the mixing bottle and 11 . of 0.4 M-phosphate buffer (pH 8.0) in the inlet bottle. Fractions of $7.5 \mathrm{ml}$. were collected at $18 \mathrm{~min}$. intervals and the buffer was changed to $0.5 \mathrm{M}$-phosphate $(\mathrm{pH} \mathrm{8.0)}$ at fraction 173. All the buffers contained $2 \times 10^{-5} \mathrm{M}$-pyridoxal phosphate and $10^{-4} \mathrm{M}$-reduced glutathione.

The crude extract was prepared for the column as follows. Nucleic acids were precipitated by addition of $1.9 \mathrm{ml}$. $\mathrm{M}-\mathrm{MnCl}_{2}$ to $25 \mathrm{ml}$. extract. After stirring for $15 \mathrm{~min}$. the mixture was centrifuged and the precipitate removed (15 min., $4600 \mathrm{~g}$ ). Then $9.67 \mathrm{~g}$. $\left(\mathrm{NH}_{4}\right)_{2} \mathrm{SO}_{4}$ was added to $26 \mathrm{ml}$. of the supernatant solution and the mixture stirred for $10 \mathrm{~min}$. After centrifugation (15 min., $4600 \mathrm{~g}$ ) the precipitate was taken up in dialysis buffer (0.02 $\mathrm{M}$-phosphate) and dialysed for $3 \mathrm{hr}$. against $1 \mathrm{l}$. of the same buffer. The final volume was $11.3 \mathrm{ml}$. of which $11 \mathrm{ml}$. was chromatographed. All operations were carried out at $0-5^{\circ}$.

Protein estimations. Protein was estimated by using the Folin phenol reagent as described by Lowry, Rosebrough, Farr \& Randall (1951).

\section{RESULTS}

\section{The site of the serine effect}

Indole is now considered to be a breakdown product of indole-3-glycerol phosphate rather than, as previously thought, a normal intermediate in tryptophan synthesis (Yanofsky, 1960). A number of bacterial mutants have been isolated which accumulate indole but, except in the case of Escherichia coli strain 7-4, there has been no report of serine being required for indole production. If the effect of serine on the 
production of indole by $E$. coli strain 7-4 were due to the fact that, as with Neurospora crassa mutant $t d_{71}$ (De Moss \& Bonner, 1959), it stimulated the conversion indole-3-glycerol phosphate $\rightarrow$ indole, restriction of the available serine should cause the accumulation of indole-8-glycerol phosphate. Restriction of available serine could be achieved in two ways, either by using the double mutant which also required serine or glycine for growth ( $E$. coli strain T2-15) or, alternatively, by using cell-free extracts which could not form serine from the available substrates.

Experiments with whole organisms. From a nutrient agar slope $\left(24 \mathrm{hr} ., 37^{\circ}\right)$ of the double mutant Escherichia coli strain T2-15, three flasks of mineral salts + citrate + glucose medium (10 ml. in $50 \mathrm{ml}$. flasks), each containing a different concentration of serine, were inoculated to give an initial population of about $2 \times 10^{6}$ bacteria $/ \mathrm{ml}$. The flasks were incubated for $18 \mathrm{hr}$. at $37^{\circ}$ with vigorous shaking and then sampled for indole and indole-3-glycerol phosphate determinations. Table 1 shows that as the concentration of serine was decreased 20 -fold the ratio of indole-3-glycerol phosphate to indole increased some 100-fold, indicating that serine probably did play some part in the conversion of indole-3-glycerol phosphate to indole by this strain.

Table 1. The accumulation products of Escherichia coli strain T 2-15 (double mutant requiring tryptophan and serine or glycine) when groron with limiting amounts of serine

Organisms grown on basal medium* for $18 \mathrm{hr}$. with $5 \mu \mathrm{g}$. L-tryptophan/ml. and DL-serine as indicated.

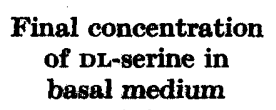

(M)

$2 \times 10^{-2}$

$10^{-8}$

\begin{tabular}{|c|c|}
\hline \multicolumn{2}{|c|}{$\begin{array}{l}\text { Product formed } \\
(\mu \mathrm{mole} / \mathrm{ml} .)\end{array}$} \\
\hline Indole & $\operatorname{InGP} \uparrow$ \\
\hline $9 \cdot 1$ & 0.45 \\
\hline $\begin{array}{l}9 \cdot 6 \\
0 \cdot 096\end{array}$ & 1.0 \\
\hline
\end{tabular}

Ratio:

InGP/indole

0.049

$0 \cdot 104$

$5 \cdot 8$

* Medium as described in methods for preparation of cell extracts with the casein hydrolysate omitted.

+ The accumulated material was probably predominantly indole-3-glycerol but was considered equivalent to InGP for the purposes of the experiment.

Experiments with cell extracts. The results given above were confirmed with cell extracts of Escherichia coli mutant strain 7-4 which were allowed to metabolize anthranilic deoxyribulotide, the intermediate immediately preceding indole-3glycerol phosphate (Smith \& Yanofsky, 1960). Table 2 shows that indole formation from anthranilic deoxyribulotide was stimulated 25 -fold by the addition of serine. Furthermore, the conversion indole-3-glycerol phosphate $\rightarrow$ indole was increased fivefold when serine was added.

\section{Examination of the effect of serine on indole formation}

Indole formation in the presence and absence of serine. Table 2 shows that some indole was formed in the absence of serine when the ASP enzyme was incubated with indole-3-glycerol phosphate. Since the enzyme had been precipitated 3 times with ammonium sulphate it seemed unlikely that this indole formation was due to traces of serine remaining from the crude extract. It appeared more likely that 
Table 2. Effect of serine on the formation of indole-3-glycerol phosphate and indole by a cell-free extract of Escherichia coli strain 7-4

Reaction mixture A consisted of anthranilic deoxyribulotide (0.44 $\mu \mathrm{mole})$ and phosphate buffer (pH 7.9; $50 \mu$ moles); mixture B contained indole-3-glycerol phosphate ( $0.18 \mu \mathrm{mole})$, phosphate buffer (pH 7.0;50 $\mu$ mole) and Escherichia coli strain $7-4$ ASP extract (0.02 ml.) in a final volume of $1.0 \mathrm{ml}$. with the additions shown. Incubation was at $37^{\circ}$ for 20 min. The contents of the tubes were then assayed for indole and indole-3-glycerol phosphate (InGP; see Methods).

$\begin{array}{lcc} & \text { Product (m } \mu \text { mole) } \\ \text { Addition to reaction mixture A } & \overbrace{\text { InGP }}^{\text {Indole }} \\ \begin{array}{l}\text { None } \\ \text { DL-serine (30 } \mu \text { mole) }\end{array} & 84 & 2 \\ \text { Addition to reaction mixture B } & & 50 \\ \text { None } \\ \text { DI-serine (30 } \mu \text { mole) }\end{array}$

some serine-independent indole formation was taking place. The components and additions involved in this serine-independent reaction will be called the basal system. Those mutant preparations and additions required to form indole in the presence of serine will be called the serine system. Hydroxylamine, a potent inhibitor of those reactions of tryptophan synthetase which require pyridoxal phosphate, slightly stimulates as a rule the conversion indole-3-glycerol phosphate $\rightarrow$ indole (Yanofsky \& Rachmeler, 1958). Table 3 shows that the basal system was not affected by hydroxylamine, whereas in the serine system, hydroxylamine acted as an inhibitor, apparently competing with serine for the available pyridoxal phosphate. Inhibition by low concentrations of hydroxylamine provided indirect evidence that pyridoxal phosphate might also be involved with serine in the stimulation of the conversion of indole-3-glycerol phosphate to indole by this altered tryptophan synthetase.

Table 3. Effect of hydroxylamine on indole formation by the basal and serine systems

The reaction mixture contained: indole-3-glycerol phosphate, $0 \cdot 18 \mu$ mole; phosphate buffer (pH 7.0), $50 \mu$ mole and in Expt. 1, 0.01 ml. crude Escherichia coli strain 7-4 extract, or in Expt. 2, 0.02 ml. of ASP enzyme together with various amounts of DLserine and hydroxylamine as shown. Incubation time, $20 \mathrm{~min}$. Final volume $1 \mathrm{ml}$.

\begin{tabular}{|c|c|c|c|}
\hline \multirow[b]{2}{*}{ Experiment } & \multicolumn{2}{|c|}{ Substance added ( $\mu$ mole) } & \multirow{2}{*}{$\begin{array}{c}\text { Indole } \\
\text { formed } \\
\text { (m } \mu \text { mole) }\end{array}$} \\
\hline & DL-Serine & Hydroxylamine & \\
\hline $\mathbf{1}$ & $\begin{array}{c}\text { None } \\
\text { None } \\
60 \\
60\end{array}$ & $\begin{array}{l}\text { None } \\
1 \\
\text { None } \\
1\end{array}$ & $\begin{array}{r}5 \\
4 \\
88 \\
5\end{array}$ \\
\hline 2 & $\begin{array}{c}\text { None } \\
100 \\
100 \\
100 \\
100 \\
10 \\
10 \\
10 \\
10\end{array}$ & $\begin{array}{l}\text { None } \\
\text { None } \\
0 \cdot 01 \\
0 \cdot 1 \\
1 \\
\text { None } \\
0 \cdot 01 \\
0 \cdot 1 \\
1\end{array}$ & $\begin{array}{r}4 \\
80 \\
71 \\
19 \\
5 \\
62 \\
23 \\
5 \\
5\end{array}$ \\
\hline
\end{tabular}


Effect of $\mathrm{pH}$ value on basal and serine reactions. The $\mathrm{pH}$ value of the incubation mixture over the range $\mathrm{pH} 7-9$ (Fig. 1) affected the basal and serine systems differently. The curves obtained may be compared with those in Fig. 2 obtained with normal tryptophan synthetase. The curve for indole formation by the basal system (Fig. 1) resembles that for the conversion indole-3-glycerol phosphate $\rightarrow$ indole by normal tryptophan synthetase (Fig. 2). The curve for indole formation by the serine system (Fig. 1) more closely resembles that for the serine and pyridoxal

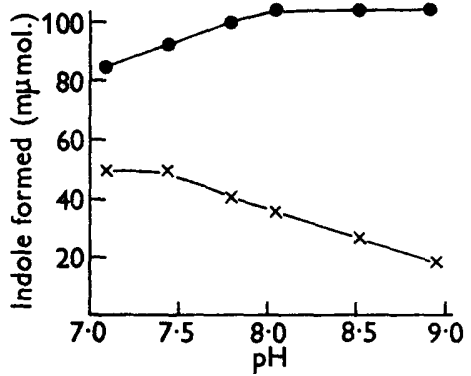

Fig. 1

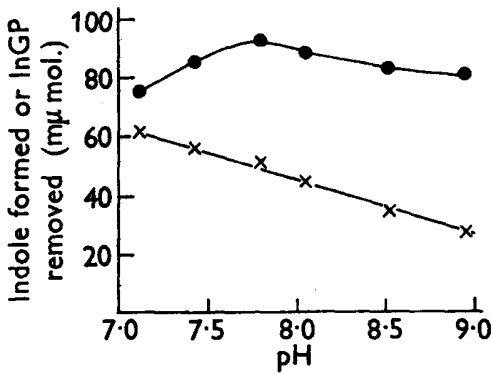

Fig. 2

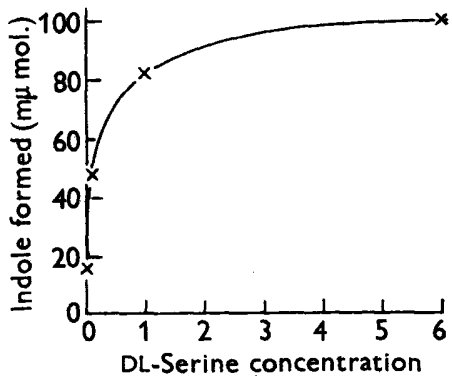

$\left(10^{2} \times M\right)$

Fig. 3

Fig. 1. The effect of $\mathrm{pH}$ on the conversion indole-3-glycerol phosphate $\rightarrow$ indole by the serine and basal systems with Escherichia coli strain 7-4 extract. The reaction mixtures were : for serine system, InGP $(0 \cdot 18 \mu \mathrm{mole})$, DL-serine $(60 \mu \mathrm{mole})$, pyridoxal phosphate (0.03 $\mu$ mole), normal A (86 units*) crude $E$. coli $7-4$ extract (0.01) ml.; for basal system, InGP $(0.18 \mu \mathrm{mole})$, hydroxylamine (1 $\mu$ mole), normal A (86 units*) crude $E$. coli strain $7-4$ extract $(0.04 \mathrm{ml}$.) together with $0.5 \mathrm{M}$-tris buffer $(50 \mu \mathrm{mole})$ in final volume $1 \mathrm{ml}$. Incubation times: serine system 20 min.; basal system 80 min. Serine system, -0; basal system, $x-x$.

* Units measured in indole $\rightarrow$ tryptophan reaction.

Fig. 2. The effect of pH value on the conversion indole-3-glycerol phosphate (InGP) $\rightarrow$ tryptophan and InGP $\rightarrow$ indole by normal tryptophan synthetase. The reaction mixtures were: for InGP $\rightarrow$ tryptophan reaction; InGP (0.18 $\mu \mathrm{mole})$, DL-serine (60 $\mu \mathrm{mole})$, pyridoxal phosphate (0.03 $\mu$ mole), saturated aqueous $\mathrm{NaCl}$ solution (0.03 ml.), normal component A (10 units*), normal protein B (2 units*); for InGP $\rightarrow$ indole reaction; InGP (0.18 $\mu$ mole), hydroxylamine (1 $\mu$ mole), normal component A (150 units*), normal component $B$ (40 units*), with tris buffer $(50 \mu$ mole). Incubation time 20 min. Final volume $1 \mathrm{ml}$. InGP $\rightarrow$ tryptophan, -O; InGP $\rightarrow$ indole, $x \rightarrow x$.

* Units measured in indole $\rightarrow$ tryptophan reaction.

Fig. 3. The effect of serine concentration on the rate of indole formation. The reaction mixture contained indole-3-glycerol phosphate $(0 \cdot 18 \mu$ mole $)$, phosphate buffer, pH 7.0 (50 $\mu$ mole), ASP enzyme from Escherichia coli strain 7-4, (0.02 ml.) with serine as indicated. Final volume $1 \mathrm{ml}$; incubation time $20 \mathrm{~min}$. 
phosphate-dependent formation of tryptophan by normal tryptophan synthetase (Fig. 2).

Specificity of L-serine. Some amino acids were tested as possible substitutes for DL-serine in the serine system (Table 4). L-Serine was twice as active as DL-serine on a molar basis, while D-serine had a slight stimulatory effect; this may have been due to contamination of the $D$-serine with small amounts of $L$-serine. The other amino acids tested were inactive.

Table 4. Indole synthesis with various amino acids related to serine

The reaction mixture was as in Table 3. Enzyme from Escherichia coli strain 7-4 (ASP preparation, $0.02 \mathrm{ml}$.) with the amino acids as shown.

\begin{tabular}{|c|c|c|}
\hline Addition & $\begin{array}{c}\text { Final } \\
\text { concentration } \\
\text { (M) }\end{array}$ & $\begin{array}{c}\text { Indole } \\
\text { formed } \\
(\mathbf{m} \mu \text { mole })\end{array}$ \\
\hline None & - & 10 \\
\hline DL-Serine & 0.06 & 93 \\
\hline I-Serine & 0.03 & 100 \\
\hline D-Serine & 0.03 & 25 \\
\hline DL-Homoserine & 0.06 & 10 \\
\hline DL-Threonine & 0.06 & 8 \\
\hline L-Cysteine & $0 \cdot 03$ & 14 \\
\hline Glycine & 0.03 & 14 \\
\hline
\end{tabular}

Serine saturation curve. Figure 3 shows the effect of increasing concentrations of serine on indole formation from indole-3-glycerol phosphate. The $K_{A}$ for DLserine estimated from the curve is about $1.3 \times 10^{-3} \mathrm{M}$ which is of the same order as the $K_{\mathbf{M}}$ for serine with normal tryptophan synthetase $\left(K_{\mathbf{M}}\right.$ for L-serine $=1.7 \times$ $10^{-3} \mathrm{M}$; C. Yanofsky, unpublished).

\section{Pyridoxal phosphate and the serine reaction}

The inhibition of the serine stimulation by hydroxylamine was strong presumptive evidence that pyridoxal phosphate was concerned in the serine system. However, indole formation by the ASP enzyme was only stimulated to a variable small degree or not at all by added pyridoxal phosphate, despite the fact that ammonium sulphate precipitations usually removed much of the bound pyridoxal phosphate (C. Yanofsky, personal communication). However, after dialysis of $0.5 \mathrm{ml}$. of ASP preparation for $2 \mathrm{hr}$. against $1 \mathrm{l}$. of $0.02 \mathrm{~m}$ tris buffer $(\mathrm{pH} 7 \cdot 8$ ) it was possible by adding pyridoxal phosphate in the serine system to show stimulation of indole formation (1·5-fold) by mutant preparations.

\section{Separation of the $A$ and $B$ proteins of the tryptophan} synthetase of Escherichia coli mutant strains 7-4

The two protein components A and B of Escherichia coli tryptophan synthetase can be separated by chromatography on cellulose ion exchangers (Crawford \& Yanofsky, 1958). To learn more about the peculiarities of the tryptophan synthetase of $E$. coli strain mutant $7-4$ the two component proteins were separated and examined individually. After chromatography of a cell-free extract of Escherichia coli strain 7-4 on DEAE cellulose (see Methods) the fractions obtained were assayed 
for component $A$ activity in the indole $\rightarrow$ tryptophan reaction in the presence of an excess (10 units) of normal B protein (Fig. 4a). After the first peak of component $A\left(A_{7-4}\right)$ was located the fractions were examined for component $B$ by measuring the conversion indole-3-glycerol phosphate $\rightarrow$ indole (in the presence of serine and an excess of $A_{7-4}$ ). Figure $4 b$ shows that $B_{7-4}$ activity was detected in two peaks. Examination of fraction 154 indicated that the addition of $\mathbf{A}_{\mathbf{7 - 4}}$ was not necessary for this fraction to catalyse the conversion indole-3-glycerol phosphate $\rightarrow$ indole. Therefore, the first $B_{7-4}$ peak probably represented an $A B$ complex (Crawford \& Yanofsky, 1958). This was confirmed by assaying fractions 140 to 190 for component $\mathbf{A}$ activity using excess normal $\mathbf{B}$ protein and measuring the conversion

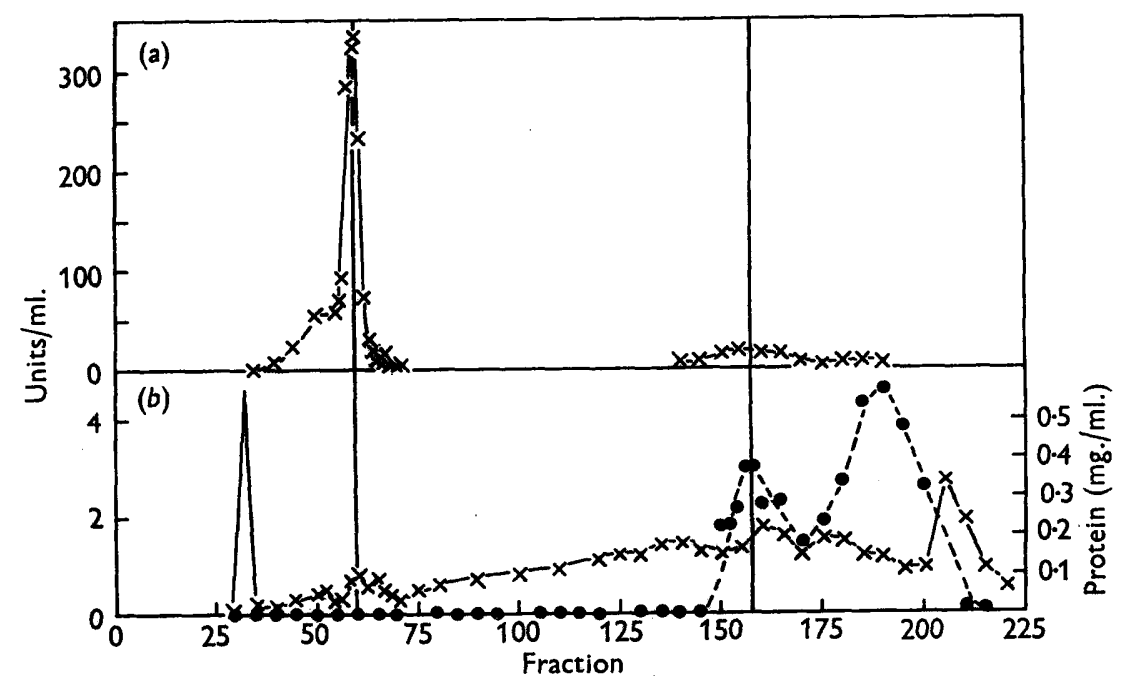

Fig. 4. Chromatography of tryptophan synthetase from Escherichia coli strain 7-4 on DEAE cellulose. Details of assay methods in text. (a) Component A activity, $x-\times$; (b) component $B$ activity, -0 ; protein concentration, $x-x$.

indole $\rightarrow$ tryptophan (Fig. $4 a$ ). The second peak of $B_{7-4}$ activity contained only low amounts of $\boldsymbol{A}_{\mathbf{7 - 4}}$. Both $\mathbf{A}_{\mathbf{7 - 4}}$ and $\mathrm{B}_{\mathbf{7 - 4}}$ were concentrated by pooling the appropriate fractions, precipitating the proteins with ammonium sulphate at $60 \%$ of saturation, and redissolving the precipitates in $0 \cdot 1 \mathrm{~m}$-tris buffer (pH 7.8). Purified $B_{7-4}$ protein was stored in buffer containing pyridoxal phosphate and reduced glutathione (see Methods).

\section{Experiments with the separated $\mathbf{A}_{7-4}$ and $\mathbf{B}_{7-4}$ components}

Component $\mathbf{A}_{7-4}$ appeared to be a normal $\mathbf{A}$ protein; in the presence of normal $B$ protein it catalysed all reactions characteristic of normal A protein. Component $B_{7-4}$ was obviously an altered component; in the presence of $A_{7-4}$ or other normal component $A$ it failed to convert indole to tryptophan. Furthermore, serine stimulated the conversion indole-8-glycerol phosphate $\rightarrow$ indole by a mixture of $\mathbf{B}_{\mathbf{7 - 4}}$ and normal A protein.

The addition of serine to a mixture of normal $A$ and $B$ proteins in the presence of 
indole-3-glycerol phosphate and pyridoxal phosphate eliminated indole formation from indole-3-glycerol phosphate because of the much faster conversion of the latter to tryptophan (Table 5).

On the other hand, a mixture of $\mathbf{B}_{\mathbf{7 - 4}}$ and normal $A$ protein formed indole from indole-3-glycerol phosphate both in the presence and absence of serine (Table 5) as expected on the basis of the experiments with the ASP extract. Purified $B_{7-4}$ protein had some activity when measured in the serine system without added A protein (Table 5); this can be explained by the small amount of $\mathbf{A}_{\mathbf{7 - 4}}$ that was present (see Fig. 4).

Table 5. The effect of serine on the conversion of indole-3-glycerol phosphate to indole with $\mathrm{B}_{7-4}$ protein and the components of normal tryptophan synthetase

The reaction mixture consisted of the reagents listed in the Table together with indole-3-glycerol phosphate (0.18 $\mu$ mole) and phosphate buffer (pH 7.0; $50 \mu$ mole). In Expts. 1 and $3(a)$, hydroxylamine (1 $\mu$ mole) was added; in Expts. 2 and $3(b)$, pyridoxal phosphate $(0.03 \mu$ mole) was added. Final volume $1 \mathrm{ml}$. Incubation times: Expt. 1, 80 min.; Expt. 2, 30 min.; Expt. 3, 30 min.

\begin{tabular}{|c|c|c|c|c|c|c|}
\hline Experiment & $\begin{array}{c}\text { Normal A } \\
\text { protein } \\
\text { (units)* }\end{array}$ & $\begin{array}{c}\mathbf{A}_{7-4} \\
\text { protein } \\
\text { (units)* }\end{array}$ & $\begin{array}{c}\text { Normal B } \\
\text { protein } \\
\text { (units)* }\end{array}$ & $\begin{array}{c}\mathbf{B}_{7-4} \\
\text { protein } \\
\text { (ml.) }\end{array}$ & $\begin{array}{c}\text { Serine } \\
\text { added } \\
\text { ( } \mu \text { mole) }\end{array}$ & $\begin{array}{c}\text { Indole } \\
\text { formed } \\
\text { (m } \mu \text { mole/ } \\
20 \text { min.) }\end{array}$ \\
\hline $1(a)$ & 560 & - & - & 0.02 & 一 & 22 \\
\hline (b) & - & 一 & - & $0 \cdot 02$ & 一 & $<1$ \\
\hline $\begin{array}{r}2(a) \\
(b)\end{array}$ & $\begin{array}{c}56 \\
-\end{array}$ & - & - & $\begin{array}{l}0.02 \\
0.02\end{array}$ & $\begin{array}{l}60 \\
60\end{array}$ & $\begin{array}{r}87 \\
5\end{array}$ \\
\hline $\begin{array}{r}3(a) \\
(b)\end{array}$ & - & $\begin{array}{l}26 \\
13\end{array}$ & $\begin{array}{l}80 \\
40\end{array}$ & - & $\overline{60}$ & $\begin{array}{r}31 \\
<1\end{array}$ \\
\hline
\end{tabular}

* Units measured in the indole $\rightarrow$ tryptophan reaction. In Expts. $1(a)$ and $2(a)$ the normal $A$ protein added was sufficient to saturate the $B_{7-4}$ protein used.

It was impossible to obtain reaction rates for the three reactions catalysed by tryptophan synthetase with either of the two components in excess, since the $B_{7-4}$ protein of course failed to catalyse the indole $\rightarrow$ tryptophan reaction. Further, this B protein could not be used in excess in the basal system, since at the concentration of enzyme required the preparation became inhibitory to the reaction.

The ratio of reaction rates for the indole $\rightarrow$ tryptophan and indole-3-glycerol phosphate $\rightarrow$ indole reactions with normal A protein and excess normal B protein in the first case, and normal $A$ and excess $B_{7-4}$ plus serine and pyridoxal phosphate in the second case, was $1: 0 \cdot 05$. The ratio of reaction rates for the same two reactions using normal A protein with normal B component was 1:0.03 (Yanofsky, 1960). It is clear then, that the addition of serine to the mutant system restored the ratio to nearly normal but did not accelerate the indole-3-glycerol phosphate $\rightarrow$ indole reaction to a point where it would be comparable with the serine requiring reactions carried out by normal $A$ and $B$ components.

Saturation of $B_{7-4}$ by normal $A$. With normal tryptophan synthetase components about a three-fold excess of one component was necessary to saturate fully the other component for maximal activity in the conversion indole $\rightarrow$ tryptophan (Crawford \& Yanofsky, 1958). In Fig. 5 it can be seen that the curve for the saturation of normal protein $B$ by normal $A$ in the conversion indole-3-glycerol phosphate $\rightarrow$ 
indole was almost identical with that obtained for the conversion indole $\rightarrow$ tryptophan (Fig. 5).

It was of interest to examine the saturation curves for $B_{7-4}$ protein in both the serine and basal systems (Fig. 6). A striking difference was detected; in the absence of serine 25 times more protein $A$ was required for half saturation of $B_{7-4}$ than in its presence.

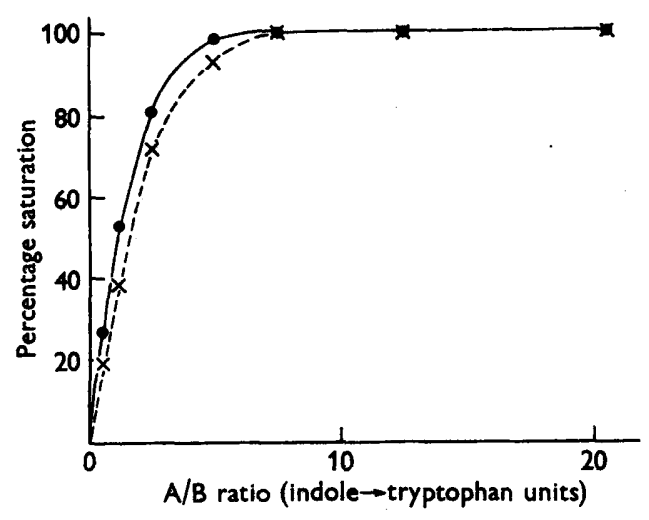

Fig. 5

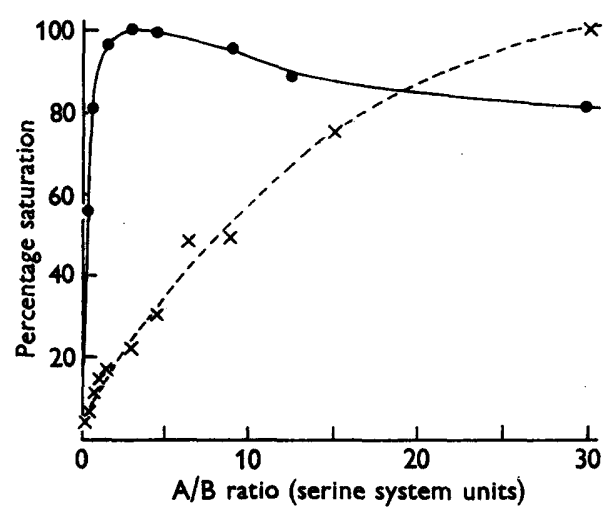

Fig. 6

Fig. 5. The saturation of normal $B$ protein by normal $A$ protein as measured in the conversion indole $\rightarrow$ tryptophan and the conversion indole-3-glycerol phosphate (ÍnGP) $\rightarrow$ indole. The reaction mixtures were: $(a)$ indole $\rightarrow$ tryptophan: phosphate buffer pH 7.0 (50 $\mu$ mole), indole $(0.4 \mu$ mole $)$, DL-serine $(60 \mu$ mole $)$, pyridoxal phosphate $(0.03 \mu$ mole), saturated aqueous $\mathrm{NaCl}$ solution ( $0.03 \mathrm{ml}$ ), normal B (3.2 units), various amounts of normal A protein; (b) InGP $\rightarrow$ indole: InGP (0.18 $\mu$ mole), phosphate buffer pH 7.0 (50 $\mu$ mole), hydroxylamine (1 $\mu$ mole), normal B (26 units), various concentrations of normal A protein. Incubation time $20 \mathrm{~min}$. for both tests. Units are measured in the indole $\rightarrow$ tryptophan reaction. Indole $\rightarrow$ tryptophan, -0 ; InGP $\rightarrow$ indole, $\times \cdots \times$.

Fig. 6. The saturation of $B_{7-4}$ protein by normal $A$ protein in the serine and basal systems. The reaction mixtures were: for serine system; indole-3-glycerol phosphate (0.18 $\mu$ mole), DL-serine (60 $\mu$ mole), pyridoxal phosphate (0.03 $\mu$ mole), phosphate buffer pH 7.0 (50 $\mu \mathrm{mole})$, purified $B_{7-4}$ protein preparation $(0.03 \mathrm{ml}$.$) , and normal B$ protein as indicated; for basal system; as above with serine and pyridoxal phosphate omitted and hydroxylamine (1 $\mu$ mole) added. Final volume $1 \mathrm{ml}$; incubation times: serine system $30 \mathrm{~min}$; basal system $80 \mathrm{~min}$. Serine system, - ; basal system, $\times \cdots \times$.

\section{DISCUSSION}

It seems probable from the findings reported here that the mutation which affects the tryptophan synthetase in Escherichia coli 7-4 leads to the production of an altered enzyme system with characteristics similar to those of the tryptophan synthetase of the mutant of Neurospora crassa described by DeMoss \& Bonner (1959). Experiments with whole organisms and cell extracts of $E$. coli strain 7-4 have shown that serine and probably pyridoxal phosphate have a marked effect on the conversion indole-3-glycerol phosphate $\rightarrow$ indole although neither of these compounds has any effect on this reaction with normal tryptophan synthetase. The present observations thus extend the similarities of mutational effects on this enzyme system in the two organisms. A major difference between the two systems, however, is the ready dissociation of the tryptophan synthetase from $E$. coli into 
two protein components A and B (Crawford \& Yanofsky, 1958). This property of the $\boldsymbol{E}$. coli system has permitted the localization of the mutational defect in $E$. coli strain 7-4 to the $B$ protein. The participation of serine and pyridoxal phosphate in a reaction involving an altered $B$ protein lends further support to the suggestion of Crawford \& Yanofsky (1958) that protein B provides the surface on which the serine + pyridoxal phosphate complex is combined during those reactions of tryptophan synthetase in which this complex is involved.

Three types of experiments differentiate the conversion indole-3-glycerol phosphate $\rightarrow$ indole in the presence and in the absence of serine: (i) the serine system is strongly inhibited by a low concentration of hydroxylamine; (ii) the $\mathrm{pH}$-activity curves for the two systems are different; (iii) curves for the saturation of $B_{7-4}$ protein by normal $A$ protein have marked differences in the serine and basal systems.

The function of serine (presumably as a Schiff base with pyridoxal phosphate) in the serine system is of interest. It does not act as a substrate in the conversion indole-3-glycerol phosphate $\rightarrow$ indole but it is possible that it is changed to some other compound by the A B protein complex during the course of the reaction. It was thought that if serine were attacked during indole formation, pyruvate would be a likely end product. Experiments designed to detect pyruvate production by the specific method of Friedmann \& Haugen (1943) were clearly negative. The affinity for serine is fairly low $\left(K_{\mathrm{a}}\right.$ about $\left.1.3 \times 10^{-3} \mathrm{M}\right)$ and with the concentrations of serine necessary to obtain a significant reaction it was not practicable to look for serine removal,

It has been suggested (DeMoss \& Bonner, 1959) that in mutants of Neurospora crassa similar to Escherichia coli strain 7-4, serine and pyridoxal phosphate might be required to maintain the active site of the altered enzyme in its 'proper' configuration for cleavage of indole-3-glycerol phosphate. This suggestion is supported and extended by the experiment shown in Fig. 4. The amount of normal $A$ protein required for half saturation of $B_{7-4}$ protein in the basal system is about 25 times that required for the serine system. This suggests that one function of serine and pyridoxal phosphate in the conversion indole-3-glycerol phosphate $\rightarrow$ indole by the tryptophan synthetase of $E$. coli strain 7-4 is to assist in binding the A and B components into an enzymically effective complex.

One of us (F.G.) is indebted to the Carnegie Corporation of New York which made this work possible while on leave from the University of Melbourne and to the Department of Biological Sciences at Stanford University for its hospitality.

This work was supported by grants from the U.S. Public Health Service and the National Science Foundation (U.S.A).

\section{REFERENCES}

Crawrord, I. P. \& Yanofsky, C. (1958). On the separation of the tryptophan synthetase of Escherichia coli into two protein components. Proc. nat. Acad. Sci., Wash. $44,1161$.

DeMoss, J. A. \& Bonner, D. M. (1959). Studies on normal and genetically altered tryptophan synthetase from Neurospora crassa. Proc. nat. Acad. Sci., Wash. 45, 1405.

Friedmann, T. E. \& Haugen, G. E. (1943). Pyruvic acid. II. The determination of keto acids in blood and urine. J. biol. Chem. 147, 415.

Gibson, F., Jones, M. I. \& Teltscher, H. (1956). The synthesis of indole by washed cell suspensions of Escherichia coli. Biochem. J. 64, 132. 
Lowry, O. H., Rosebrough, N. J., Farr, A. L. \& Randali, R. J. (1951). Protein measurement with the Folin phenol reagent. J. biol. Chem. 193, 265.

SMTTH, O. \& YANOFsKy, C. (1960). 1-[0-carboxyphenylamino]1-deoxyribulose-5-phosphate, a new intermediate in the biosynthesis of tryptophan. J. biol. Chem. 235, 2051.

Vogel, H. J. \& BonNer, D. M. (1956). A convenient growth medium for $E$. coli and some other microorganisms. Microbial Genetics Bulletin 13, 48.

YANOFsky, C. (1955). Tryptophan synthetase from Neurospora. Methods in Enzymology, 2, p. 233. Ed. S. P. Colowick and N. O. Kaplan. New York: Academic Press, Inc.

YaNOFsKY, C. (1956). The enzymatic conversion of anthranilic acid to indole. J. biol. Chem. 223, 171.

YANOFsky, C. (1959). A second reaction catalyzed by the tryptophan synthetase of Escherichia coli. Biochim. biophys. Acta, 31, 408.

YANOFSKY, C. (1960). The tryptophan synthetase system. Bact. Rev. 24, 221.

YANOFSKY, C. \& RACHMELER, M. (1958). The exclusion of free indole as an intermediate in the biosynthesis of tryptophan in Neurospora crassa. Biochim. biophys. Acta, 28, 640.

YANOFsKY, C. \& StadLen, J. (1958). The enzymatic activity associated with the protein immunologically related to tryptophan synthetase. Proc. nat. Acad. Sci., Wash. 44, 245. 